\title{
USE OF SCAR-PCR IN DIAGNOSTICS OF STEM BASE PATHOGENS OF THE Rhizoctonia AND Oculimacula GENUS
}

\author{
Grzegorz Lemańczyk \\ Department of Phytopathology and Molecular Mycology, University of Technology and Life Sciences, \\ Kordeckiego 20, 85-225 Bydgoszcz, Poland, \\ e-mail: Grzegorz.Lemanczyk@utp.edu.pl
}

Received: 13.05.2011

\begin{abstract}
The aim of the paper is to compare the efficacy of SCAR-PCR assay and conventional diagnostic technique (visual assessment, isolation on PDA medium) in the identification of fungi from the genera Rhizoctonia and Oculimacula from winter triticale, rye, and barley during the shooting stage. The usefulness of molecular diagnosis of fungal pathogens in crop plants has been demonstrated. The application of SCAR-PCR assay allowed early detection of the following pathogens: $O$. yallundae, $O$. acuformis, $R$. cerealis and $R$. solani, in plant tissues. This method was particularly effective in detection of $R$. solani. The research showed the usefulness of PCR markers for early detection of fungal pathogens, even if symptoms were not visible. Using the PCR technique, especially in combination with conventional methods, substantially increases the precision and effectiveness of disease diagnostics.
\end{abstract}

Key words: PCR assay, sharp eyespot, eyespot, diagnostics, barley, triticale, rye

\section{INTRODUCTION}

Foot diseases are one of the most important problems in cereal production. Among them, eyespot caused by Oculimacula yallundae (formerly Tapesia yallundae) and $O$. acuformis (formerly T. acuformis) is regarded as the most dangerous disease in temperate climate ( $\mathrm{Crous}$ et al. 2003; R a y et al. 2006; $\mathrm{C} \mathrm{h}$ a p $\mathrm{m}$ a $\mathrm{n}$ et al. 2008). It can be found on many cereal species, including wheat, barley, oats, triticale, and rye. These cereals can also be infected by another stem base pathogen - Rhizoctonia cerealis, the main causal agent of sharp eyespot. This disease causes lower yield losses than eyespot (Crome y et al. 2002). Due to the fact that fungicides are effective only against eyespot, it becomes increasingly important. More and more symptoms of sharp eyespot are observed under field conditions ( $\mathrm{L}$ e m a ń c z y k, 2010a). Unfortunately, the symptoms of these two diseases are similar and they can be sometimes confused.

Visual diagnosis of stem base diseases is very difficult, especially when the infection is caused by more than one pathogen. In such cases, one can easily make a mistake, especially in the early stages of the disease. In addition, symptoms may be obscured by the second pathogen. Traditionally, confirmation of visual assessments concerning the presence of the causal agent of stem base diseases is based on the isolation and identification of pathogens on artificial nutrient media. However, saprotrophic organisms are numerously isolated from diseased tissues, because of the slower growth of typical pathogens obtained using such type of identification method (B a te $\mathrm{m}$ a $\mathrm{n}$ and Kw a śn a, 1999).

Molecular methods based on polymerase chain reaction (PCR), especially SCAR-PCR, may be very helpful in the diagnosis of plant diseases. Analysis of molecular markers using a SCAR (Sequence Characterized Amplified Region) allows one to obtain a species-specific amplicon ( $\mathrm{N} \mathrm{i} \mathrm{c} \mathrm{h} \mathrm{o} 1 \mathrm{~s}$ o n et al. 1997; $€$ u k a n ow ski et al. 2009). The use of species-specific primers allows the identification of the pathogen, often before the appearance of disease symptoms, also directly in infected tissues without their isolation ( $\mathrm{Ni}$ chols on and Parry, 1996). Early detection of the pest allows for quick application of the relevant plant protection product. It is extremely important because fungicide treatments against stem base diseases are recommended to be applied in the early stages of plant development, when the plant often does not have any visible sign of disease. It should be emphasized that 
the fungicides effectively control eyespot, but not sharp eyespot. For this reason, it is very important to accurately determine the threats posed by various pathogens in order to conduct fungicide treatment only when it is really necessary.

SCAR is a fast and relatively inexpensive technique. However, it is used mainly in the identification of pathogens of wheat, but there is little information regarding its application in the case of other cereals. The aim of the study was to examine the usefulness of the SCAR-PCR technique, in comparison with traditional methods in the diagnosis of stem base pathogens (from the genus Rhizoctonia and Oculimacula) of winter forms of rye, triticale and barley, in the initial stage of shooting.

\section{MATERIALS AND METHODS}

\section{Survey and visual assessment}

Plants of winter rye (Secale cereale L.), cultivar Dańkowskie Złote, were sampled from production fields located in Mochełek (17 $\left.51^{\prime} \mathrm{E}, 53^{\circ} 13^{\prime} \mathrm{N}\right)$, whereas winter triticale ( $x$ Triticosecale Wittm. ex A.Camus), cultivar Gniewko, and winter barley (Hordeum vulgare L.), cultivar Traminer, were collected from fields in Chrzastowo $\left(17^{\circ} 33^{\prime} \mathrm{E}, 5^{\circ} 10^{\prime} \mathrm{N}\right)$. In the laboratory, plants were thoroughly and carefully rinsed off the soil and divided into groups according to the type of symptoms:

$\mathrm{R}$ - stems with pale brown, spindle-shaped, clearly defined spots with a dark edge, typical symptoms for sharp eyespot,

$\mathrm{O}$-stems with brown, spindle-shaped spots, typical symptoms of eyespot,

F - stems with brown streaks, lines or leaking, symptoms typical of Fusarium foot rot,

$\mathrm{H}$ - healthy stems.

In 2008, 32 plants of barley, 29 of triticale, 31 of rye, and in 200735 plants of rye were chosen for further analysis. Samples were collected in the initial shooting stage - GS 31 ( $\mathrm{Zadoks}$ et al. 1974). The choice of this phase was caused by a commonly recommended time of eyespot control. Isolation of fungi was conducted on artificial media and confirmation of their presence in plant tissues was done with PCR assay (Doyle and Doyle, 1990; Nichols on and Parry, 1996).

\section{Isolation of fungi and identification by morphology}

Ten $2 \mathrm{~mm}$ fragments of the stem base were cut from each sample of every studied cereal species. In the case of visible disease symptoms, the fragments were taken from the places where changes were most pronounced. From macroscopically healthy stems, the pieces were cut from the tillering node.

The fragments were washed for 45 minutes in running tap water, separately for each plant, surface sterilized in $1 \% \mathrm{AgNO}_{3}$ solution for 15 seconds and washed three times for $1 \mathrm{~min}$. in sterile distilled water. Five stem base fragments were put onto Petri dishes with Potato Dextrose Agar (PDA) enriched with streptomycin (50mg streptomycin per 1L of medium). The samples were incubated at $22^{\circ} \mathrm{C}$ and transferred onto agar slants. When the mycelium appeared on the medium surface, the fragments were taken from the plates, frozen $\left(-30^{\circ} \mathrm{C}\right)$ and used for further molecular analysis.

Fungal isolates were identified with mycological keys. Particular species of the Rhizoctonia genus were distinguished using the technique of staining fungal hyphae (B a n d o n i, 1979). Moreover, the linear growth rate of mycelium was determined on PDA medium. Identification of $O$. yallundae and $O$. acuformis was based on the available papers ( $\mathrm{Cr}$ e i $\mathrm{g}$ h t o n, 1989; Crous et al. 2003; K or bas , 2008).

\section{Extraction of DNA and molecular identification}

Total DNA isolation was carried out according to the modified protocol described by D o y le and D o y le (1990). The same fragments, which had been previously placed on PDA medium, were molecularly tested for the presence of $R$. cerealis and $R$. solani, $O$. yallundae, and $O$. acuformis. They were pre-homogenized and placed in $1.5 \mathrm{ml}$ Eppendorf tubes. Then, they were crushed in liquid nitrogen for $5 \mathrm{~min}$. into fine powder and poured with $600 \mu \mathrm{l}$ of extraction buffer $(0.24 \mathrm{ml} 5 \%$ CTAB, $0.17 \mathrm{ml} 5 \mathrm{M}$ $\mathrm{NaCl}, 0.02 \mathrm{ml} 5 \mathrm{M}$ EDTA, $0.06 \mathrm{ml} 1 \mathrm{M}$ tris- $\mathrm{HCl} \mathrm{pH} 8$, $1.2 \mu \mathrm{l} \beta$-mercaptoetanol, $0.12 \mathrm{~g}$ PVP, $0.12 \mathrm{ml} \mathrm{H}_{2} \mathrm{O}$ miliQ). The tubes were incubated in water bath at $65^{\circ} \mathrm{C}$ for $40 \mathrm{~min}$., and their content was mixed by inverting

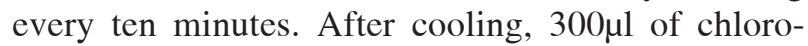
phorm and isoamyl alcohol mixture $(24: 1 \mathrm{v} / \mathrm{v})$ and $300 \mu \mathrm{l}$ of phenol solution with a $\mathrm{pH}$ of 8.0 was added to every tube and vortexed. The tubes were centrifuged (12000 RPM, $10 \mathrm{~min}$.) and the upper phase (supernatant) was transferred into a new tube and mixed with $600 \mu$ l of chlorophorm and isoamyl alcohol mixture $(24: 1 \mathrm{v} / \mathrm{v})$ by inverting the tubes for 3 minutes. After centrifugation, the supernatant was transferred to a new tube with $50 \mu \mathrm{l} 5 \mathrm{M} \mathrm{NaOH}$ and $700 \mu \mathrm{l}$ of frozen $95 \%$ ethanol was added to precipitate DNA. It was washed twice with $300 \mu$ l of frozen $70 \%$ ethanol, centrifuged, ethanol was discarded and DNA was left to dry. Efficiency of DNA isolation was measured by its concentration determined with a NanoDrop ND1000 spectrophotometer (NanoDrop Technologies, 
Inc. USA). DNA concentration used for PCR assay was $150 \mathrm{ng} \times \mu^{-1}$.

The PCR reactions were carried out using a Taq PCR Core Kit (QIAGEN Inc.) in a total volume of $12.5 \mu$. Each reaction mixture contained $3.9 \mu \mathrm{l}$ $\mathrm{H}_{2} \mathrm{O}, 2.5 \mu \mathrm{l} 5 \times$ buffer $\mathrm{Q}, 1.25 \mu \mathrm{l} 10 \times$ PCR buffer, $0.5 \mu \mathrm{l}$ $\mathrm{MgCl}_{2}, 0.25 \mu \mathrm{dNTP}$ mix, 0.75 primer I (Table 1), primer 0.75 II, $0.1 \mu \mathrm{l} \mathrm{Taq}$ polymerase, $2.5 \mu \mathrm{l}$ DNA. The PCR amplification was carried out in a thermocycler (Eppendorf Mastercycler ep gradient, Germany) in 30 cycles using cycling conditions presented in Table 2.

The PCR products were checked by electrophoresis of $5 \mu \mathrm{l}$ of product in a $1.4 \%$ agarose gel containing ethidium bromide to stain the DNA. The gel was visualized immediately after the run using an ultraviolet light box. Pictures were taken with a digital camera using the program Biocapt (Vilbert Lourmat, France). Perfect ${ }^{\mathrm{TM}} 100$ bp DNA Ladder (Eurx, Poland) was used as a molecular size standard for PCR products.

To avoid false-negative results caused by too small amount of PCR product invisible on the agarose gel, a second series of reactions was carried out, using the amplification product of the previous reactions as a template.

Table 1.

List of SCAR primers used for detection of plant pathogens

\begin{tabular}{|c|c|c|c|c|}
\hline Pathogen & Primer & Primer sequence $\left(5^{\prime}-3^{\prime}\right)$ & Fragment size & Reference \\
\hline \multirow{2}{*}{ R. cerealis } & $\mathrm{Rc} 2 \mathrm{~F}$ & 5'-AAAACTGGCAACCCTTGGTG-3' & \multirow{2}{*}{800 bp } & \multirow{2}{*}{ Nicholson and Parry, 1996} \\
\hline & $\operatorname{Rc} 2 \mathrm{R}$ & 5'-TAACTCACCACTCCAGCC-3' & & \\
\hline \multirow{2}{*}{ R. solani } & ITS1 & 5'-TCCGTAGGTGAACCTGCGG-3' & \multirow{2}{*}{$550 \mathrm{bp}$} & \multirow{2}{*}{ Johanson et al., 1998} \\
\hline & GMRS-3 & 5'-AGTGGAACCAAGCATAACACT-3' & & \\
\hline \multirow{2}{*}{ O. yallundae (type W) } & TyV5F & 5'-CGC CCA GGT AGA GAT TCA GG-3' & \multirow{2}{*}{$600 \mathrm{bp}$} & \multirow{2}{*}{ Nicholson et al., 1997} \\
\hline & TyV5R & 5'-GGG AGA AAA CGA CGA GAT GC-3’ & & \\
\hline \multirow{2}{*}{ O. acuformis (type R) } & $\mathrm{Ta} 05 \mathrm{~F}$ & 5'-GTA TCG GAC GGA GAT CCA GC-3' & \multirow{2}{*}{$330 \mathrm{bp}$} & \multirow{2}{*}{ Nicholson et al., 1997} \\
\hline & Ta05R & 5'-TTG CTC AGT GCA TTG TCG G-3' & & \\
\hline
\end{tabular}

Table 2.

PCR conditions used in the study

\begin{tabular}{lclc}
\hline \multicolumn{1}{c}{ Step } & Temperature $\left[{ }^{\circ} \mathrm{C}\right]$ & Pathogen & Time (min) \\
\hline Initial denaturation & 94 & & 3 \\
Denaturation & 94 & & 1 \\
Annealing & 58.5 & R. cerealis & 1 \\
& 58.5 & R. solani & 1 \\
& 60.4 & O. yallundae & 1 \\
& 60.6 & O. acuformis & 1 \\
Elongation & 72 & & 2 \\
Final extension & 72 & & 5 \\
Cooling & 4 & & - \\
\hline
\end{tabular}

\section{RESULTS}

\section{Survey and visual assessment}

Visual plant health assessments conducted at shooting stage (GS 31) revealed relatively low severity of diseases being researched. Sharp eyespot symptoms were noted only on rye. In 2007, they were observed on $0.5 \%$ of the plants, and in 2008 on $1.0 \%$
(Table 3). Eyespot was visible on $0.5-3.5 \%$ of the plants. During the ripening (GS 77), there were also no symptoms of sharp eyespot on barley, whereas on the other cereal species they were observed on 4.0$6.5 \%$ of the plants. Barley also showed a low number of eyespot symptoms $(1.5 \%)$, while they were often noted on rye, especially in 2008 (32\%), and triticale $(9.5 \%)$. 
Table 3.

Share of stems (in \%) with sharp eyespot and eyespot symptoms calculated on the basis of macroscopic assessment

\begin{tabular}{lccccc}
\hline \multirow{2}{*}{ Species } & \multirow{2}{*}{ Year } & \multicolumn{2}{c}{ Sharp eyespot } & \multicolumn{2}{c}{ Eyespot } \\
\cline { 3 - 6 } & & GS 31 & GS 77 & GS 31 & GS 77 \\
\hline Rye & 2007 & 0.5 & 4.0 & 0.5 & 7.5 \\
& 2008 & 1.0 & 5.0 & 3.5 & 32 \\
Triticale & 2008 & 0.0 & 6.5 & 3.0 & 9.5 \\
Barley & 2008 & 0.0 & 0.0 & 1.0 & 1.5 \\
\hline
\end{tabular}

\section{Isolation of fungi} and morphological identification

Saprotrophic fungi were mostly isolated both from stem bases with lesions as well as from those with no visible disease symptoms (Table 4-7). These fungi were mostly represented by the genus Penicil- lium and Trichoderma. A single stem base was usually colonised by fungi representing various species or genera. Occasionally, pathogenic fungi were also obtained, among them Fusarium avenaceum, F. culmorum, $F$. solani and $F$. merismoides, which was also isolated from visually healthy plants.

Table 4.

Identification of the genus Rhizoctonia and Oculimacula causing rye stem base diseases with PCR assay, isolation on PDA and visual assessment, in 2007 (GS 31)

\begin{tabular}{|c|c|c|c|c|c|c|c|c|c|c|}
\hline \multirow{2}{*}{$\begin{array}{c}\text { No. of } \\
\text { stem }\end{array}$} & \multirow{2}{*}{$\begin{array}{c}\text { Visual } \\
\text { assessment }\end{array}$} & \multicolumn{4}{|c|}{ PCR detection } & \multicolumn{5}{|c|}{ Isolation on PDA medium } \\
\hline & & $\mathrm{Rc}^{5}$ & $\mathrm{Rs}^{6}$ & $\mathrm{Oy}^{7}$ & $\mathrm{Oa}^{8}$ & $\mathrm{Rc}$ & Rs & Oy & $\mathrm{Oa}$ & Others $^{11}$ \\
\hline 1 & $\mathrm{R}^{1}$ & $-9 /-^{10}$ & $-1+$ & $-1-$ & $-1-$ & - & - & - & - & $\mathrm{P}^{12}(3)$ \\
\hline 2 & $\mathrm{R}$ & $-1-$ & $-1-$ & $-1-$ & $-1-$ & - & - & - & - & $\mathrm{Fc}^{13}(1), \mathrm{T}^{14}(3)$ \\
\hline 3 & $\mathrm{O}^{2}$ & $-1-$ & $+/+$ & $-1-$ & $-1-$ & - & - & - & - & - \\
\hline 4 & $\mathrm{O}$ & $-1-$ & $-1-$ & $-1-$ & $-1-$ & - & - & - & - & $\mathrm{T}(2)$ \\
\hline 5 & $\mathrm{~F}^{3}$ & $-1-$ & $-1-$ & $-1-$ & $-1-$ & - & - & - & - & $\mathrm{Fc}(3), \mathrm{M}^{15}(1)$ \\
\hline 6 & $\mathrm{~F}$ & $-1-$ & $-1-$ & $-1-$ & $-1-$ & - & - & - & - & $\operatorname{Fc}(1)$ \\
\hline 7 & $\mathrm{H}^{4}$ & $-1-$ & $+/+$ & $-1-$ & $-1-$ & - & - & - & - & - \\
\hline 8 & $\mathrm{H}$ & $-1-$ & $+/+$ & $-1-$ & $-1-$ & - & - & - & - & - \\
\hline 9 & $\mathrm{H}$ & $-1-$ & $-1+$ & $-1-$ & $-1-$ & - & - & - & - & $\mathrm{P}(3)$ \\
\hline 10 & $\mathrm{H}$ & $-1-$ & $-1+$ & $-1-$ & $-1-$ & - & - & - & - & $\mathrm{Fa}^{16}(1), \mathrm{P}(2)$ \\
\hline 11 & $\mathrm{H}$ & $-1-$ & $+/+$ & $-/-$ & $-1-$ & - & - & - & - & $\mathrm{T}(1)$ \\
\hline 12 & $\mathrm{H}$ & $-1-$ & $+/+$ & $-/-$ & $-1-$ & - & - & - & - & - \\
\hline 13 & $\mathrm{H}$ & $-1-$ & $-1-$ & $-/-$ & $-1-$ & - & - & - & - & - \\
\hline 14 & $\mathrm{H}$ & $-1-$ & $-1-$ & $-1-$ & $-1-$ & - & - & - & - & - \\
\hline 15 & $\mathrm{H}$ & $-1-$ & $-1-$ & $-1-$ & $-1-$ & - & - & - & - & $\mathrm{P}(2)$ \\
\hline 16 & $\mathrm{H}$ & $-1-$ & $+/+$ & $-1-$ & $-1-$ & - & - & - & - & - \\
\hline 17 & $\mathrm{H}$ & $-1-$ & $-1-$ & $-1-$ & $-1-$ & - & - & - & - & $\mathrm{P}(1)$ \\
\hline 18 & $\mathrm{H}$ & $-1-$ & $-1-$ & $-1-$ & $-1-$ & - & - & - & - & - \\
\hline 19 & $\mathrm{H}$ & $-1-$ & $-1-$ & $-1-$ & $-1-$ & - & - & - & - & $\mathrm{An}^{17}(1), \mathrm{P}(2)$ \\
\hline 20 & $\mathrm{H}$ & $-1-$ & $-1-$ & $-1-$ & $-1-$ & - & - & - & - & $\mathrm{P}(2)$ \\
\hline 21 & $\mathrm{H}$ & $-1-$ & $-1-$ & $-1-$ & $-1-$ & - & - & - & - & $\mathrm{P}(1)$ \\
\hline 22 & $\mathrm{H}$ & $-1-$ & $-1-$ & $-1-$ & $-1-$ & - & - & - & - & $\mathrm{P}(4)$ \\
\hline 23 & $\mathrm{H}$ & $-1-$ & $-1-$ & $-1-$ & $-1-$ & - & - & - & - & - \\
\hline 24 & $\mathrm{H}$ & $-1-$ & $-1-$ & $-1-$ & $-1-$ & - & - & - & - & - \\
\hline 25 & $\mathrm{H}$ & $-1-$ & $-1+$ & $-1-$ & $-1-$ & - & - & - & - & $\mathrm{P}(3)$ \\
\hline 26 & $\mathrm{H}$ & $-1-$ & $-1-$ & $-1-$ & $-1-$ & - & - & - & - & $\mathrm{T}(2)$ \\
\hline 27 & $\mathrm{H}$ & $-1-$ & $-1-$ & $-1-$ & $-1-$ & - & - & - & - & $\mathrm{P}(3)$ \\
\hline 28 & $\mathrm{H}$ & $-1-$ & $-1+$ & $-1-$ & $-1-$ & - & - & - & - & - \\
\hline 29 & $\mathrm{H}$ & $-1-$ & $-1+$ & $-1-$ & $-1-$ & - & - & - & - & $\mathrm{Aa}^{18}(1), \mathrm{Fc}(1), \mathrm{Py}^{19}(1)$ \\
\hline 30 & $\mathrm{H}$ & $-1-$ & $-1-$ & $-1-$ & $-1-$ & - & - & - & - & $\mathrm{T}(2)$ \\
\hline 31 & $\mathrm{H}$ & $-1-$ & $-1-$ & $-1-$ & $-1-$ & - & - & - & - & $\mathrm{Fa}(1)$ \\
\hline 32 & $\mathrm{H}$ & $-1-$ & $-1-$ & $-1-$ & $-1-$ & - & - & - & - & - \\
\hline 33 & $\mathrm{H}$ & $-1-$ & $+/+$ & $-1-$ & $-1-$ & - & - & - & - & $\operatorname{An}(1), P(3)$ \\
\hline 34 & $\mathrm{H}$ & $-1-$ & $+/+$ & $-1-$ & $-1-$ & - & - & - & - & $\mathrm{T}(4)$ \\
\hline 35 & $\mathrm{H}$ & $-1-$ & $+/+$ & $-1-$ & $-1-$ & - & - & - & - & $\mathrm{P}(2), \mathrm{T}(3)$ \\
\hline
\end{tabular}


Table 5.

Identification of the genus Rhizoctonia and Oculimacula causing rye stem base diseases with PCR assay, isolation on PDA and visual assessment, in 2008 (GS 31)

\begin{tabular}{|c|c|c|c|c|c|c|c|c|c|c|}
\hline \multirow{2}{*}{$\begin{array}{l}\text { No. of } \\
\text { stem }\end{array}$} & \multirow{2}{*}{$\begin{array}{c}\text { Visual } \\
\text { assessment }\end{array}$} & \multicolumn{4}{|c|}{ PCR detection } & \multicolumn{5}{|c|}{ Isolation on PDA medium } \\
\hline & & $\mathrm{Rc}^{5}$ & $\mathrm{Rs}^{6}$ & $\mathrm{Oy}^{7}$ & $\mathrm{Oa}^{8}$ & $\mathrm{Rc}$ & Rs & Oy & $\mathrm{Oa}$ & Others ${ }^{11}$ \\
\hline 1 & $\mathrm{R}^{1}$ & $-9 /+^{10}$ & $-1+$ & $-1-$ & $-1-$ & - & - & - & - & $\mathrm{P}^{12}(1), \mathrm{T}^{13}(1)$ \\
\hline 2 & $\mathrm{R}$ & $-/-$ & $-/+$ & $-1-$ & $-1-$ & - & - & - & - & $\mathrm{P}(1)$ \\
\hline 3 & $\mathrm{R}$ & $-1+$ & $-/+$ & $-1-$ & $-1-$ & - & - & - & - & $\mathrm{T}(1)$ \\
\hline 4 & $\mathrm{R}$ & $-1+$ & $-1+$ & $-1-$ & $-1-$ & - & - & - & - & $\mathrm{P}(3)$ \\
\hline 5 & $\mathrm{O}^{2}$ & $-1-$ & $-1+$ & $-1-$ & $-1+$ & - & - & - & (4) & $\mathrm{Mm}^{14}(1), \mathrm{P}(1)$ \\
\hline 6 & $\mathrm{O}$ & $-1-$ & $-/+$ & $+/-$ & $-1-$ & - & - & - & - & $\operatorname{Ap}^{15}(1), P(2), \mathrm{Ph}^{16}(1)$ \\
\hline 7 & $\mathrm{O}$ & $-/-$ & $-/+$ & $-/+$ & $-1-$ & - & - & (1) & - & $\mathrm{P}(1)$ \\
\hline 8 & $\mathrm{O}$ & $-/-$ & $-1+$ & $-/+$ & $-1-$ & - & - & (3) & - & $\mathrm{Mr}^{17}(1), \mathrm{P}(5), \mathrm{T}(2)$ \\
\hline 9 & $\mathrm{O}$ & $-/-$ & $-1+$ & $+/-$ & $-1-$ & - & - & (1) & - & $\mathrm{P}(2), \mathrm{T}(1)$ \\
\hline 10 & $\mathrm{O}$ & $-1-$ & $-/+$ & $-1-$ & $-1-$ & - & - & - & - & $\mathrm{T}(1)$ \\
\hline 11 & $\mathrm{O}$ & $-/-$ & $-/+$ & $-1-$ & $-1-$ & - & - & - & - & $\mathrm{P}(3)$ \\
\hline 12 & $\mathrm{O}$ & $-1-$ & $-/+$ & $-1-$ & $-1-$ & - & - & - & - & - \\
\hline 13 & $\mathrm{O}$ & $-/-$ & $-/+$ & $-1-$ & $-1-$ & - & - & - & - & $\mathrm{P}(1)$ \\
\hline 14 & $\mathrm{O}$ & $-/-$ & -l- & $-/+$ & $-1-$ & - & - & - & - & - \\
\hline 15 & $\mathrm{O}$ & $-/-$ & $-1-$ & $-1-$ & $-1-$ & - & - & - & - & $\mathrm{Fc}^{18}(1), \mathrm{T}(1)$ \\
\hline 16 & $\mathrm{O}$ & $-/-$ & $-1+$ & $-1-$ & $-1-$ & - & - & - & - & $\mathrm{T}(1)$ \\
\hline 17 & $\mathrm{~F}^{3}$ & $-1-$ & $-/+$ & $-1-$ & $-1-$ & - & - & - & - & - \\
\hline 18 & $\mathrm{~F}$ & $-/-$ & $-/+$ & $-1-$ & $-1-$ & - & - & - & - & $\mathrm{P}(1)$ \\
\hline 19 & $\mathrm{~F}$ & $-/-$ & $-1+$ & $-1-$ & $-1-$ & - & - & - & - & $\operatorname{Mr}(4), T(1)$ \\
\hline 20 & F & $-/-$ & $+/+$ & $-1-$ & $-1-$ & - & - & (2) & - & $\mathrm{P}(4), \mathrm{T}(1)$ \\
\hline 21 & $\mathrm{O}$ & $-/-$ & $+/+$ & $-1-$ & $-1-$ & - & - & (3) & - & $\operatorname{Mm}(1), P(1)$ \\
\hline 22 & F & $-/-$ & $+/+$ & $-1-$ & $-1-$ & - & - & - & - & $\mathrm{P}(2)$ \\
\hline 23 & $\mathrm{~F}$ & $-/-$ & $+/+$ & $-1-$ & $-1-$ & - & - & - & - & $\operatorname{Af}^{19}(1)$ \\
\hline 24 & $\mathrm{H}^{4}$ & $-/-$ & $+/+$ & $-1-$ & $-1-$ & - & - & - & - & $\mathrm{An}^{20}(4)$ \\
\hline 25 & $\mathrm{H}$ & $-/-$ & $+/+$ & $-1-$ & $-1-$ & - & - & - & - & - \\
\hline 26 & $\mathrm{H}$ & $-/-$ & $+/+$ & $-1-$ & $-1-$ & - & - & - & - & - \\
\hline 27 & $\mathrm{H}$ & $-1-$ & $+/+$ & $-1-$ & $-1-$ & - & - & - & - & $\mathrm{P}(4), \mathrm{Ph}(1)$ \\
\hline 28 & $\mathrm{H}$ & $-1-$ & $-1+$ & $-1-$ & $-1-$ & - & - & - & - & $\mathrm{P}(2)$ \\
\hline 29 & $\mathrm{H}$ & $-1-$ & $-/+$ & $-1-$ & $-1-$ & - & - & - & - & $\mathrm{Fc}(1), \mathrm{P}(3)$ \\
\hline 30 & $\mathrm{H}$ & $-1-$ & $-/+$ & $-1-$ & $-1-$ & - & - & - & - & $\operatorname{Af}(1), P(1)$ \\
\hline 31 & $\mathrm{H}$ & $-1-$ & $-1-$ & $-/+$ & $-1-$ & - & - & - & - & $\operatorname{An}(1), P(1), T(1)$ \\
\hline
\end{tabular}

${ }^{1} \mathrm{R}$ - sharp eyespot; ${ }^{2} \mathrm{O}$ - eyespot; ${ }^{3} \mathrm{~F}-$ Fusarium foot rot; ${ }^{4} \mathrm{H}-$ healthy ${ }^{5} \mathrm{Rc}-R$. cerealis; ${ }^{6} \mathrm{Rs}-R$. solani; ${ }^{7} \mathrm{Oy}-$ O. yallundae; ${ }^{8} \mathrm{Oa}-O$. acuformis; ${ }^{9}-$ positive result $(+)$ or negative result $(-)$ of first PCR reaction; ${ }^{10}-$ positive result $(+)$ or negative result $(-)$ of second PCR reaction; ${ }^{11}$ other fungi (in bracket number of isolates): ${ }^{12} \mathrm{P}-$ Penicillium sp.; ${ }^{13} \mathrm{~T}-$ Trichoderma sp.; ${ }^{14} \mathrm{Mm}-$ Mucor mисеdo; ${ }^{15} \mathrm{Ap}$ - Arthinium phaeospermum; ${ }^{16} \mathrm{Ph}-$ Phoma sp.; ${ }^{17} \mathrm{Mr}-$ Myrothecium roridum; ${ }^{18} \mathrm{Fc}-$ F. culmorum $;{ }^{19} \mathrm{Af}-$ Aspergillus fumigatus; ${ }^{20} \mathrm{An}-A$. niger

In 2008 only $O$. yallundae was isolated from stem bases of rye (Table 4,5$)$. This species was found in 4 plants with brown, spindle-shaped spots, and in one plant with brown streaks. It should be noted here that this fungus was not isolated from all fragments obtained after cutting the individual stem bases. It was often accompanied by saprotrophic fungi.

$O$. yallundae was isolated on PDA medium from 6 barley stems with disease symptoms (Table 6). $O$. acuformis and fungi from the Rhizoctonia genus were not obtained.

Among the fungi from the Rhizoctonia genus, only one $R$. solani isolate was obtained on PDA medium from the stem of triticale (Table 7). There was also isolated $O$. yallundae from 4 plants of this cereal.

\section{Molecular identification with PCR assay}

PCR assay (primers ITS1 and GMRS-3) revealed the presence of $R$. solani in rye stem bases, giving the expected amplification product of $550 \mathrm{bp}$. In 2007, after the first PCR series, this species was found in 9 stems and after the second series of PCR assay, which used the amplification product of the previous PCR assay as a template, it was found in 14 stems (Table 4). 
In 2008, molecular assays revealed the presence of the following pathogens: $R$. solani in 28 rye stems, including those with no disease symptoms; $R$. cerealis in 3 plants with sharp eyespot symptoms; $O$. yallundae in 6 plants, and $O$. acuformis in one plant. It should be noted that these results in most cases corresponded to the identification based on visual assessments of disease symptoms (Table 5).

The presence of $O$. yallundae in 6 plants of barley and $R$. solani in 28 plants was detected with PCR assay (Table 6). PCR assays confirmed only the presence of $R$. solani in triticale (Table 7).

Table 6.

Identification of the genus Rhizoctonia and Oculimacula causing barley stem base diseases with PCR assay, isolation on PDA and visual assessment (GS 31)

\begin{tabular}{|c|c|c|c|c|c|c|c|c|c|c|}
\hline \multirow{2}{*}{$\begin{array}{l}\text { No. of } \\
\text { stem }\end{array}$} & \multirow{2}{*}{$\begin{array}{c}\text { Visual } \\
\text { assessment }\end{array}$} & \multicolumn{4}{|c|}{ PCR detection } & \multicolumn{5}{|c|}{ Isolation on PDA medium } \\
\hline & & $\mathrm{Rc}^{5}$ & $\mathrm{Rs}^{6}$ & $\mathrm{Oy}^{7}$ & $\mathrm{Oa}^{8}$ & $\mathrm{Rc}$ & Rs & Oy & $\mathrm{Oa}$ & Others ${ }^{11}$ \\
\hline 1 & $\mathrm{O}^{1}$ & $-8 /-^{9}$ & $+/+$ & $-1+$ & $-1-$ & - & - & - & - & $\mathrm{T}^{11}(1)$ \\
\hline 2 & $\mathrm{O}$ & $-1-$ & $-1+$ & $-1-$ & $-1-$ & - & _- & - & - & $\mathrm{P}^{12}(1), \mathrm{Th}^{13}(1)$ \\
\hline 3 & $\mathrm{O}$ & $-1-$ & $-1+$ & $-1-$ & $-1-$ & - & - & - & - & $\mathrm{T}(1)$ \\
\hline 4 & $\mathrm{O}$ & $-1-$ & $-/+$ & $+/+$ & $-1-$ & - & - & (2) & - & $\operatorname{An}^{14}(1), \operatorname{As}^{15}(1), \mathrm{Ph}^{16}(2)$ \\
\hline 5 & $\mathrm{O}$ & $-1-$ & $-1+$ & $-1-$ & $-1-$ & - & - & (3) & - & $\mathrm{Ch}^{17}(1), \mathrm{P}(3)$ \\
\hline 6 & $\mathrm{O}$ & $-1-$ & $-1+$ & $-1-$ & $-1-$ & - & - & (3) & - & $\mathrm{P}(2)$ \\
\hline 7 & $\mathrm{O}$ & $-1-$ & $-1+$ & $-1-$ & $-1-$ & - & _- & - & - & $\operatorname{An}(1)$ \\
\hline 8 & $\mathrm{O}$ & $-1-$ & $-1+$ & $-1-$ & $-1-$ & - & - & (4) & - & $\mathrm{Gr}^{18}(1), \mathrm{P}(3), \mathrm{T}(1)$ \\
\hline 9 & $\mathrm{O}$ & $-1-$ & $-1+$ & $+/-$ & $-1-$ & - & _- & (3) & - & $\mathrm{P}(1)$ \\
\hline 10 & $\mathrm{O}$ & $-1-$ & $-1+$ & $-1-$ & $-1-$ & - & - & - & - & - \\
\hline 11 & $\mathrm{O}$ & $-1-$ & $+/+$ & $-1-$ & $-1-$ & - & - & - & - & An (1), T(1) \\
\hline 12 & $\mathrm{O}$ & $-1-$ & $-1+$ & +/+ & $-1-$ & - & - & (6) & - & $\mathrm{P}(1)$ \\
\hline 13 & $\mathrm{~F}^{2}$ & $-1-$ & $-1+$ & $-1-$ & $-1-$ & - & - & - & - & $\mathrm{T}(1)$ \\
\hline 14 & $\mathrm{~F}$ & $-1-$ & $-1+$ & $-1-$ & $-1-$ & - & _- & - & - & $\mathrm{M}^{19}(1), \mathrm{P}(4), \mathrm{T}(1)$ \\
\hline 15 & $\mathrm{~F}$ & $-1-$ & $-1+$ & $-1-$ & $-1-$ & - & - & - & - & $\mathrm{P}(1), \mathrm{Tp}^{20}(1), \mathrm{Tv}^{21}(3)$ \\
\hline 16 & $\mathrm{~F}$ & $-1-$ & $-1+$ & $-1-$ & $-1-$ & - & - & - & - & $\mathrm{T}(1)$ \\
\hline 17 & $\mathrm{~F}$ & $-1-$ & $-1+$ & $-1-$ & $-1-$ & - & - & - & - & $\mathrm{P}(1), \mathrm{T}(1)$ \\
\hline 18 & $\mathrm{~F}$ & $-1-$ & $-1+$ & $-1-$ & $-1-$ & - & - & - & - & $\mathrm{T}(1), \mathrm{M}(1)$ \\
\hline 19 & $\mathrm{~F}$ & $-1-$ & $-1+$ & $-1-$ & $-1-$ & - & _- & - & - & $\mathrm{Ch}(1), \mathrm{P}(5)$ \\
\hline 20 & $\mathrm{~F}$ & $-1-$ & $+/+$ & $-1-$ & $-1-$ & - & - & - & - & $\mathrm{T}(1)$ \\
\hline 21 & $\mathrm{~F}$ & $-1-$ & $-1+$ & $-1-$ & $-1-$ & - & - & - & - & $\mathrm{P}(3)$ \\
\hline 22 & $\mathrm{~F}$ & $-1-$ & $-1+$ & $-1-$ & $-1-$ & - & - & - & - & $\mathrm{T}(1)$ \\
\hline 23 & $\mathrm{~F}$ & $-1-$ & $+/+$ & $-1-$ & $-1-$ & - & - & - & - & $\mathrm{T}(1)$ \\
\hline 24 & $\mathrm{H}^{3}$ & $-1-$ & $-1-$ & $-1-$ & $-1-$ & - & _- & - & - & $\mathrm{P}(5)$ \\
\hline 25 & $\mathrm{H}$ & $-1-$ & $-1-$ & $-1-$ & $-1-$ & - & - & - & - & $\mathrm{Rh}^{22}(1)$ \\
\hline 26 & $\mathrm{H}$ & $-1-$ & $-1+$ & $-1-$ & $-1-$ & - & - & - & - & $\mathrm{P}(1)$ \\
\hline 27 & $\mathrm{H}$ & $-1-$ & $-1-$ & $-1-$ & $-1-$ & - & - & - & - & $\mathrm{Rh}(1)$ \\
\hline 28 & $\mathrm{H}$ & $-1-$ & $+/+$ & $-1-$ & $-1-$ & - & - & - & - & $\mathrm{T}(1)$ \\
\hline 29 & $\mathrm{H}$ & $-1-$ & $-1+$ & $-1-$ & $-1-$ & - & - & - & - & $\mathrm{T}(1)$ \\
\hline 30 & $\mathrm{H}$ & $-1-$ & $-1+$ & $-1-$ & $-1-$ & - & - & - & - & $\mathrm{P}(1), \mathrm{T}(1)$ \\
\hline 31 & $\mathrm{H}$ & $-1-$ & $-/+$ & $-1-$ & $-1-$ & - & - & - & - & $\mathrm{P}(1)$ \\
\hline 32 & $\mathrm{H}$ & $-1-$ & $-1-$ & $-1-$ & $-1-$ & - & - & - & - & $\mathrm{P}(1)$ \\
\hline
\end{tabular}

${ }^{1} \mathrm{O}$ - eyespot; ${ }^{2} \mathrm{~F}-$ Fusarium foot rot; ${ }^{3} \mathrm{H}$ - healthy; ${ }^{4} \mathrm{Rc}-R$. cerealis $;{ }^{5} \mathrm{Rs}-R$. solani $;{ }^{6} \mathrm{Oy}-$ O. yallundae $;{ }^{7} \mathrm{Oa}-O$. acuformis $;$ 8 - positive result $(+)$ or negative result $(-)$ of first PCR reaction; ${ }^{9}-$ positive result $(+)$ or negative result $(-)$ of second PCR reaction; ${ }^{10}$ other fungi (in bracket number of isolates): ${ }^{11} \mathrm{~T}$ - Trichoderma sp.; ${ }^{12} \mathrm{P}-$ Penicillium sp.; ${ }^{13} \mathrm{Th}-$ Trichoderma haruatum; ${ }^{14}$ An A. niger; ${ }^{15}$ As - Acremonium strictum; ${ }^{16} \mathrm{Ph}-$ Phoma sp.; ${ }^{17} \mathrm{Ch}-$ C. herbarum; ${ }^{18} \mathrm{Gr}-$ Gymnoascus reesii; ${ }^{19} \mathrm{Mm}-$ Mucor mucedo; ${ }^{20} \mathrm{Tp}$ - Trichoderma polysporum; ${ }^{21} \mathrm{Tv}$ - Trichoderma viride; ${ }^{22} \mathrm{Rh}-$ Rhizopus $\mathrm{sp}$.

\section{Comparison of visual disease assessment, PCR assay, and isolation on PDA}

The three analyzed methods were able to confirm only the presence of eyespot on 3 plants of barley and 4 plants of rye assessed in 2008 (Table 8). The occurrence of sharp eyespot was confirmed with a visual and molecular technique, but $R$. cerealis was not isolated on PDA medium. This resume does not include $R$. solani, since this species occurred on most plants, regardless of symptoms. In addition, during the maturity stage, there was no significant increase in the number of plants with sharp eyespot, which might suggest that this species was not the causal agent of this disease. 
Table 7.

Identification of the genus Rhizoctonia and Oculimacula causing triticale stem base diseases with PCR assay, isolation on PDA and visual assessment (GS 31)

\begin{tabular}{|c|c|c|c|c|c|c|c|c|c|c|}
\hline \multirow{2}{*}{$\begin{array}{l}\text { No. of } \\
\text { stem }\end{array}$} & \multirow{2}{*}{$\begin{array}{c}\text { Visual } \\
\text { assessment }\end{array}$} & \multicolumn{4}{|c|}{ PCR detection } & \multicolumn{5}{|c|}{ Isolation on PDA medium } \\
\hline & & $\mathrm{Rc}^{5}$ & $\mathrm{Rs}^{6}$ & $\mathrm{Oy}^{7}$ & $\mathrm{Oa}^{8}$ & $\mathrm{Rc}$ & Rs & Oy & $\mathrm{Oa}$ & Others $^{11}$ \\
\hline 1 & $\mathrm{O}^{1}$ & $-8 /-^{9}$ & $-1+$ & $-1-$ & $-1-$ & - & - & - & - & $\mathrm{T}^{11}(1)$ \\
\hline 2 & $\mathrm{O}$ & $-1-$ & $-/+$ & $-1-$ & $-1-$ & - & - & - & - & $\mathrm{Ab}^{12}(1), \mathrm{Ch}^{13}(2), \mathrm{P}^{14}(2)$ \\
\hline 3 & $\mathrm{O}$ & $-/-$ & $-/+$ & $-1-$ & $-1-$ & - & - & (3) & - & $\mathrm{Aa}^{15}(3), \mathrm{Ch}(1)$ \\
\hline 4 & $\mathrm{O}$ & $-1-$ & $-1+$ & $-1-$ & $-/-$ & - & - & - & - & $\operatorname{Ab}(1), \operatorname{Ap}^{16}(1), P(2)$ \\
\hline 5 & $\mathrm{O}$ & $-/-$ & $-1+$ & $-1-$ & $-1-$ & - & - & - & - & $\mathrm{Fm}^{17}(3), \mathrm{Fs}^{18}(2)$ \\
\hline 6 & $\mathrm{O}$ & $-1-$ & $-1+$ & $-1-$ & $-1-$ & - & - & - & - & $\mathrm{T}(1)$ \\
\hline 7 & $\mathrm{O}$ & $-1-$ & $-1-$ & $-1-$ & $-1-$ & - & - & (1) & - & $\mathrm{Aa}(2), \mathrm{P}(2)$ \\
\hline 8 & $\mathrm{O}$ & $-1-$ & $-1-$ & $-1-$ & $-1-$ & - & (1) & - & - & $\mathrm{P}(1), \mathrm{T}(1)$ \\
\hline 9 & $\mathrm{O}$ & $-1-$ & $-1-$ & $-1-$ & $-1-$ & - & - & - & - & $\mathrm{P}(4), \mathrm{T}(1)$ \\
\hline 10 & $\mathrm{O}$ & $-1-$ & $-1-$ & $-1-$ & $-1-$ & - & - & - & - & $\operatorname{Fm}(2), \operatorname{Fs}(3), P(2)$ \\
\hline 11 & $\mathrm{O}$ & $-1-$ & $-1-$ & $-1-$ & $-1-$ & - & - & - & - & $\mathrm{T}(1)$ \\
\hline 12 & $\mathrm{O}$ & $-/-$ & $-/+$ & $-1-$ & $-1-$ & - & - & - & - & $\mathrm{P}(1)$ \\
\hline 13 & $\mathrm{~F}^{2}$ & $-/-$ & $-/+$ & $-1-$ & $-1-$ & - & - & - & - & $\mathrm{P}(1)$ \\
\hline 14 & $\mathrm{~F}$ & $-/-$ & $-1+$ & $-1-$ & $-1-$ & - & - & (1) & - & $\mathrm{Rh}^{19}(1)$ \\
\hline 15 & $\mathrm{~F}$ & $-1-$ & $-1+$ & $-1-$ & $-1-$ & - & - & - & - & $\mathrm{P}(4)$ \\
\hline 16 & $\mathrm{~F}$ & $-/-$ & $-1-$ & $-1-$ & $-1-$ & - & - & (1) & - & $\mathrm{P}(1), \mathrm{T}(1)$ \\
\hline 17 & $\mathrm{~F}$ & $-1-$ & $-1-$ & $-1-$ & $-/-$ & - & - & - & - & $\mathrm{P}(1)$ \\
\hline 18 & $\mathrm{~F}$ & $-/-$ & $-1-$ & $-1-$ & $-1-$ & - & - & - & - & $\mathrm{T}(1)$ \\
\hline 19 & $\mathrm{~F}$ & $-1-$ & $-1-$ & $-1-$ & $-1-$ & - & - & - & - & $\mathrm{P}(1)$ \\
\hline 20 & $\mathrm{~F}$ & $-1-$ & $-/+$ & $-1-$ & $-1-$ & - & - & - & - & $\mathrm{P}(1), \mathrm{T}(1)$ \\
\hline 21 & $\mathrm{~F}$ & $-1-$ & $-1-$ & $-1-$ & $-1-$ & - & - & - & - & $\mathrm{P}(1)$ \\
\hline 22 & $\mathrm{H}^{3}$ & $-1-$ & $-1-$ & $-1-$ & $-1-$ & - & - & - & - & $\mathrm{T}(1)$ \\
\hline 23 & $\mathrm{H}$ & $-/-$ & $-1+$ & $-1-$ & $-1-$ & - & - & - & - & $\operatorname{An}^{20}(1), \operatorname{Fs}(1), V^{21}(1)$ \\
\hline 24 & $\mathrm{H}$ & $-1-$ & $-1+$ & $-1-$ & $-1-$ & - & - & - & - & $\mathrm{P}(2), \mathrm{T}(1)$ \\
\hline 25 & $\mathrm{H}$ & $-1-$ & $-1-$ & $-1-$ & $-1-$ & - & - & - & - & $\mathrm{P}(1)$ \\
\hline 26 & $\mathrm{H}$ & $-1-$ & $-1+$ & $-1-$ & $-1-$ & - & - & - & - & $\mathrm{P}(1)$ \\
\hline 27 & $\mathrm{H}$ & $-/-$ & $-1+$ & $-1-$ & $-1-$ & - & - & - & - & $\mathrm{T}(1)$ \\
\hline 28 & $\mathrm{H}$ & $-1-$ & $-1+$ & $-1-$ & $-1-$ & - & - & - & - & $\mathrm{P}(1)$ \\
\hline 29 & $\mathrm{H}$ & $-1-$ & $-1+$ & $-1-$ & $-1-$ & - & - & - & - & $\mathrm{P}(1), \mathrm{T}(1)$ \\
\hline
\end{tabular}

${ }^{1} \mathrm{O}$ - eyespot; ${ }^{2} \mathrm{~F}-$ Fusarium foot $\operatorname{rot} ;{ }^{3} \mathrm{H}$ - healthy; ${ }^{4} \mathrm{Rc}-$ R. cerealis $;{ }^{5} \mathrm{Rs}-$ R. solani $;{ }^{6} \mathrm{Oy}-$ O. yallundae $;{ }^{7} \mathrm{Oa}-$ O. acuformis; ${ }^{8}$ - positive result $(+)$ or negative result $(-)$ of first PCR reaction; ${ }^{9}-$ positive result $(+)$ or negative result $(-)$ of second PCR reaction; ${ }^{10}$ other fungi (in bracket number of isolates): ${ }^{11} \mathrm{~T}$ - Trichoderma sp.; ${ }^{12} \mathrm{Ab}-$ Aureobasidium bolleyi; ${ }^{13} \mathrm{Ch}-$ Cladosporium herbarum; ${ }^{14} \mathrm{P}-$ Penicillium sp.; ${ }^{15} \mathrm{Aa}-$ A. alternata $;{ }^{16} \mathrm{Ap}$-Aureobasidium pullulans; ${ }^{17} \mathrm{Fm}-$ Fusarium merismoides; ${ }^{18} \mathrm{Fs}-$ Fusarium solani;

${ }^{19} \mathrm{Rh}-$ Rhizopus sp.; ${ }^{20} \mathrm{An}-$ A. niger; ${ }^{21} \mathrm{~V}$ - Verticillium sp.

Table 8.

Comparison of the number of positively diagnosed plants with visual disease assessment, PCR assay and isolation on PDA

\begin{tabular}{|c|c|c|c|c|c|c|c|c|c|}
\hline \multirow{2}{*}{ Species } & \multirow{2}{*}{ Year } & \multicolumn{4}{|c|}{ Sharp eyespot $(R$. cerealis) } & \multicolumn{4}{|c|}{ Eyespot (O. yallundae, O. acuformis) } \\
\hline & & Visual $^{1}$ & $\mathrm{PCR}^{2}$ & $\mathrm{PDA}^{3}$ & $\mathrm{All}^{4}$ & Visual & PCR & PDA & All \\
\hline \multirow[t]{2}{*}{ Rye } & 2007 & 2 & 0 & 0 & 0 & 1 & 0 & 0 & 0 \\
\hline & 2008 & 4 & 3 & 0 & 0 & 13 & 7 & 6 & 4 \\
\hline Triticale & 2008 & 0 & 0 & 0 & 0 & 12 & 0 & 5 & 0 \\
\hline Barley & 2008 & 0 & 0 & 0 & 0 & 12 & 4 & 6 & 3 \\
\hline
\end{tabular}

${ }^{1}$ - visual assessment of disease symptoms; ${ }^{2}$ diagnosis of disease factor occurrence with PCR assay; ${ }^{3}$ - identification of disease factor on PDA; ${ }^{4}$ positive result of disease factor diagnosis using all three techniques 


\section{DISCUSSION}

The usefulness of SCAR-PCR assay for the determination of the presence of $R$. solani, $R$. cerealis, $O$. yallundae, and $O$. acuformis in the individual cereal stems was confirmed. The detection was successful regardless of disease symptoms, also in the case when the traditional method that involves isolation on microbiological media did not show their presence.

Mainly saprotrophic fungi were isolated on PDA, and only occasionally $O$. yallundae, $O$. acuformis, and R. solani were found. Rhizoctonia cerealis and Oculimacula spp., as pathogens specialized in cereal infection, grow relatively slowly on artificial media and are often overgrown by fast growing saprotrophic fungi and Fusarium spp. (B a t e $\mathrm{m}$ a $\mathrm{n}$ and $\mathrm{K} \mathrm{w}$ a ś $\mathrm{n}$ a , 1999). According to C r e i g h t o n (1989), fungi from the genus Oculimacula should not be identified as particular species on the basis of morphological features without additional tests, i.e. pathogenicity and molecular studies.

According to data presented by other authors, diagnostics carried out by traditional techniques are not always able to be confirmed with molecular assays, and vice versa (N i chols on et al. 1997; Turner et al. 1999). Ni c hol s o n and P a r r y (1996) report, however, that there is a correlation between the results of PCR, conventional isolation on artificial media, and visual assessment. Using methods based on PCR, especially in combination with conventional methods used in phytopathology, substantially increases the precision and effectiveness of diagnostics of plant diseases. Matusinsky et al. (2008), using species-specific SCAR primers, also confirmed the presence of $R$. $c e$ realis in plant tissues of cereals. $\mathrm{Nich} \mathrm{ols} \mathrm{on} \mathrm{et} \mathrm{al.}$ (2002) and Ray et al. (2004) indicated that the amount of DNA of $R$. cerealis in wheat tissue increased in particular growth stages of plants. This pathogen usually occurs in later development stages, only occasionally in earlier ones, and sometimes it is not observed at all.

Most of the papers on the use of PCR technique in plant pathogen diagnostics concern the molecular confirmation of pathogen identity previously isolated on artificial media (I z y k ow ska et al. 2005; K orbas, 2008). In this study, the presence of the examined fungi in DNA samples derived from plants was also confirmed. Previously, SCAR primers were successfully used in identification of $R$. cerealis and $R$. solani obtained from winter triticale ( $\mathrm{L}$ e m a ń c zyk, 2010a), as well as from the spring form of barley, wheat, and triticale (L e m a ń c z y k, 2010b). Their use in our study proved to be particularly effective for identifying $R$. solani in plant tissues. The fungus was found in tissues exhibiting different symptoms, as well as in symptomless plants. The presence of $R$. $c e$ realis was confirmed only in three plants, despite the fact that symptoms of sharp eyespot were noted also on other plants. This could result from a low concentration of fungal DNA preventing its detection. However, Nich ols on and Parry (1996) report that a positive result is not obtained only for concentrations lower than $1 \mathrm{pg}$ of pure DNA of $R$. cerealis. According to them, the sensitivity level is one of the most important factors in detection of pathogens. Amplification performance depends largely on purification of genomic DNA from PCR inhibitors such as polysaccharides, phenolic compounds and enzymatic proteins reducing the efficiency of reaction (W i l s o n , 1997).

PCR technique is considered very reliable (Nicholson and Parry, 1996), but SCAR primers do not always guarantee correct results. $€ \mathrm{uk} \mathrm{k} \mathrm{n} \mathrm{ow} \mathrm{s} \mathrm{ki} \mathrm{et} \mathrm{al.}$ (2009) reported the possibility of changes in sequences of genomes to which primers hybridize. This indicates that there is a risk of obtaining false-negative results that may lead to erroneous conclusions. Therefore, a negative PCR result should be treated with some caution, and in case of doubt, if possible, should be retested using a different pair of primers or analysis of ITS regions (internal transcribed spacer).

Differences in length and sequence of ITS-1 and ITS-2 regions were used to identify isolates of $R$. cerealis and $R$. solani (I r z y k o w s k a et al. 2005). ITS sequence analysis is a method used for, e.g., the determination of phylogenetic relationships between species. It allows one to identify Rhizoctonia isolates belonging to particular anastomosis groups within species in this genus (S h a ro n et al. 2006). Sequencing of ITS regions resulted in designing primer pairs specific for $\mathrm{W}$ and $\mathrm{R}$ pathotypes $(O$. yallundae and $O$. acuformis) (P o u p a rd et al. 1993).

In this research, we were not able to confirm the presence of $O$. yallundae and $O$. acuformis in all plants with disease symptoms typical for these pathogens. Łapiński et al. (2008) molecularly detected the presence of these fungi in rye, triticale during tillering and later growth stages, while there were no results for barley. It has been reported that DNA content of these pathogens in tissues increases during plant growth (R a y et al. 2004; W a l s h et al. 2005).

Oculimacula acuformis was found only in one plant. According to G $ł$ a z e k (2009), this species was more numerous on wheat fields in south-central Poland as compared to $O$. yallundae, which explains the late appearance of disease symptoms, however, plants for analysis were sampled during ripening. K o r b a s (2008) reported that $O$. yallundae predominates at shooting stage, whereas in later phases the difference in proportions among different species was significantly reduced. This explains the fact that in our study this species also dominated. $O$. yallundae colonizes plant tissue faster than $O$. acuformis, which results from its 
rapid linear growth (N i c h o l s o n et al. 2002; K or b a s 2008). Nichols on et al. (2002) and R a y et al. (2006) reported a higher content of DNA of $O$. yallundae than $O$. acuformis in the earlier growth stages of wheat.

In these studies, there was no simultaneous occurrence of $R$. cerealis, $O$. yallundae, and $O$. acuformis on the same stems. Such a situation was also reported by Nicholson and Parry (1996). Faster-growing $O$. yallundae can inhibit the development of $R$. cerealis. Therefore, in tissues showing symptoms of eyespot, apart from Oculimacula, only $R$. solani was noted as a faster growing species belonging to necrotrophic microorganisms (B a t e $\mathrm{m}$ a $\mathrm{n}$ and $\mathrm{Kw}$ a śn a, 1999).

\section{CONCLUSIONS}

1. The research showed the usefulness of PCR markers for detection of fungal pathogens, even if symptoms were not visible. The application of SCAR-PCR assay allowed early detection of $O$. yallundae, $O$. acuformis, $R$. cerealis, and $R$. solani in plant tissues.

2. Using the PCR technique, especially in combination with conventional methods, substantially increases the precision and effectiveness of disease diagnosis.

\section{Acknowledgements}

This work was supported by Project No PB 0842/P06/2005/28 from the Polish Ministry of Science and Higher Education.

\section{REFERENCES}

B a nd on i R.J., 1979. Safranin O as a rapid nuclear stain for fungi. Mycologia, 71 (4): 873-874.

Bateman G.L., Kwaśna H., 1999. Effects of number of winter wheat crops grown successively on fungal communities on wheat roots. Appl. Soil Ecol. 13 (3): 271-282

Chapman N.H., Burt C., Dong.H. Nicholson P., 2008. The development of PCR-based markers for the selection of eyespot resistance genes Pchl and Pch2. Theor. Appl. Genet. 117 (3): 425-433.

Creighton N.F., 1989. Identification of W-type and R-type isolates of Pseudocercosporella herpotrichoides. Plant Pathol. 38 (4): 484-493.

Cromey M.G., Butler R.C., Boddington H.J., Moorhead A.R., 2002. Effects of sharp eyespot on yield of wheat (Triticum aestivum) in New Zealand. New Zeal. J. Crop Hort. 30 (1): 9-17.

Crous P.W., Groenewald J.Z., Gams W., 2003. Eyespot of cereals revisited: ITS phylogeny reveals new species relationships. Eur. J. Plant Pathol. 109 (8): 841850.

Doyle J.J., Doyle J.L., 1990. Isolation of plant DNA from fresh tissue. Focus, 12 (1): 13-15.

G ła zek M., 2009. Occurrence of eyespot on winter wheat in the Central-Southern region of Poland. J. Plant Protection Res. 49 (4): 426-433.

Irzykowska L., Żółtańska E, Bocianowski J., 2005. Use of molecular and conventional techniques to identify and analyze genetic variability of Rhizoctonia ssp. isolates. Acta Agrobot. 59 (2): 19-32.

Johanson A., Turner H.C., McKay G.J., Brown A.E., 1998. A PCR-based method to distinguish fungi of the rice sheath-blight complex, Rhizoctonia solani, $R$. oryzae and $R$. oryzae-sativae. FEMS Microbiol. Lett. 162 (2): 289-294.

Korbas M., 2008. Epidemiologia łamliwości źdźbła pszenicy ozimej w Polsce. / Diagnostic of winter wheat eyespot in Poland. Rozpr. Nauk. Inst. Ochr. Roślin, 18: 68 pp (in Polish).

Le mańc zyk G., 2010a. Occurrence of sharp eyespot (Rhizoctonia cerealis) in winter triticale grown in some provinces of Poland. Phytopathologia, 56: 27-38.

Lemańczyk G., 2010b. Occurrence of sharp eyespot in spring cereals grown in some regions of Poland. J. Plant Protection Res. 50 (4): 505-512.

Łapiński M., Pszczółkowska A., Kulik T., Okorski A., Olszewski J., Fordoński G., Adamiak J., 2008. Detection of some fungal pathogens in crops using the SCAR assays. Pol. J. Natur. Sc. 23 (1): 16-34.

Łukanowski A., Baturo A., Sadowski C., 2009. Use of molecular techniques in mycological research. [In:] Understanding the Requirements for Development of Agricultural Production and of Rural Areas in the Kuyavian-Pomeranian Province as a Result of Scientific Research. E. Śliwińska, E. Spychaj-Fabisiak (eds) UTP, Bydgoszcz, pp. 57-68.

Matusinsky P., Mikolasova R., Klem K., Spitzer T., Urban T., 2008. The role of organic vs. conventional farming practice, soil management and preceding crop on the incidence of stem-base pathogens on wheat. J. Plant Dis. Protect. 115 (1): 17-22.

Nichols on P., Parry D.W., 1996. Development and use of a PCR assay to detect Rhizoctonia cerealis, the cause of sharp eyespot in wheat. Plant Pathol. 45 (5): 872-883.

Nicholson P., Rezanoor H.N., Simpson D.R., Joyce D., 1997. Differentiation and quantification of the cereal eyespot fungi Tapesia yallundae and Tapesia acuformis using a PCR assay. Plant Pathol. 46 (6): 842-856.

Nicholson P., Turner A.S., Edwards S.G., Bateman G.L., Morgan L.W., Parry D.W., Marshall J., Nuttall M., 2002. Development of stem-base pathogens on different cultivars of winter wheat determined by quantitative PCR. Eur. J. Plant Pathol. 108 (2): 163-177. 
Poupard P., Simonet P., Cavelier N., Bardin R., 1993. Molecular characterization of Pseudocercosporella herpotrichoides isolates by amplification of ribosomal DNA internal transcribed spacers. Plant Pathol. 42 (6): 873-881.

Ray R.V., Crook M.J., Jenkinson P., Edwards S.G., 2006. Effect of eyespot caused by $\mathrm{Ocu}$ limacula yallundae and $O$. acuformis, assessed visually and by competitive PCR, on stem strength associated with lodging resistance and yield of winter wheat. J. Exp. Bot. 57 (10): 2249-2257.

Ray R.V., Jenkinson P., Edwards S.G., 2004. Effects of fungicides on eyespot, caused predominantly by Oculimacula acuformis, and yield of early-drilled winter wheat. Crop Prot. 23 (12): 1199-1207.

Sharon M., Kuninaga S., Hyakumachi M., Sneh B., 2006. The advancing identification and classification of Rhizoctonia spp. using molecular and biotechnological methods compared with the classical anastomosis grouping. Mycoscience, 47 (6): 299-316.

Turner A.S., O’Hara R.B., Rezanoor H.N., Nuttall M., Smith J.N., Nicholson P., 1999. Visual disease and PCR assessment of stem base diseases in winter wheat. Plant Pathol. 48 (6): 742-748.

Walsh K., Korimbocus J., Boonham N., Jennings P., Hims M.M., 2005. Using real-time PCR to discriminate and quantify the closely related wheat pathogens Oculimacula yallundae and Oculimacula acuformis. J. Phytopathology, 153 (11-12): 715-721.

Wils on I.G., 1997. Inhibition and facilitation of nucleic acid amplification. Appl. Environ. Microbiol. 63 (10): 3741-3751.
Zadoks J.C., Chang T.T., Konzak C.F., 1974. A decimal code for the growth stages of cereals. Weed Res. 14 (6): 415-421.

\section{Zastosowanie SCAR-PCR w diagnostyce patogenów podstawy źdźbła zbóż z rodzajów Rhizoctonia i Oculimacula}

\section{Streszczenie}

Porównywano zastosowanie metody SCAR-PCR i konwencjonalnej (wizualna ocena, izolacja na pożywce PDA) w identyfikacji grzybów z rodzajów Rhizoctonia i Oculimacula na formach ozimych pszenżyta, żyta i jęczmienia, pobieranych w fazie strzelania w źdźbło. Wykazano przydatność diagnostyki molekularnej patogenów grzybowych roślin w uprawach polowych. Zastosowanie metody SCAR-PCR umożliwiło wczesne wykrycie patogenów: $O$. yallundae, $O$. acuformis, $R$. cerealis i $R$. solani w tkankach roślinnych. Detekcja molekularna okazała się szczególnie skuteczna w wykrywaniu obecności $R$. solani. Badania wskazują na użyteczność stosowania markerów PCR do wczesnego wykrywania patogenów grzybowych, również w przypadku braku objawów chorobowych. Wykorzystanie techniki PCR zwłaszcza w połączeniu z klasycznymi metodami znacząco podnosi precyzję i skuteczność diagnostyki chorób roślin. 